\title{
Beliefs about the risks of guns in the home: analysis of a national survey
}

\author{
Kim Ammann Howard, Daniel W Webster, Jon S Vernick
}

\begin{abstract}
Objectives-While epidemiological evidence suggests homes with guns are more likely to be the site of a suicide or homicide than homes without guns, the public's perception of these risks remains unknown. This study assesses the prevalence of the belief that homes with guns are safer than homes without guns, and factors associated with this belief.

Methods-Telephone interviews were conducted with a random sample of $4138 \mathrm{reg}-$ istered voters in urban areas in the US. Multinomial logistic regression was used to assess correlates of beliefs about the safety of keeping a gun in the home.

Results-Twenty nine per cent of respondents believed keeping a gun in the home makes the home more safe, $40 \%$ said less safe, $23 \%$ said it depends, and $9 \%$ were unsure. The belief that a home is more safe with a gun was associated with being male, young, completing 12 years or fewer of education, having no children living at home, Republican party affiliation, and low levels of trust in the police for protection. Prior exposure to violence and fear of victimization were not associated with the outcome.

Conclusions-Findings may increase understanding about the public's perception of the risk in keeping guns in the home and assist educational efforts to decrease the risk of these injuries.

(Injury Prevention 1999;5:284-289)
\end{abstract}

Keywords: firearms; violence; risk behavior

Although there is debate about the issue, ${ }^{12}$ the weight of evidence suggests that keeping a gun in the home increases the mortality risks of household members. The evidence that gun ownership increases risks is perhaps strongest for suicides, particularly suicides of adolescents. ${ }^{3}$ Eight case-control studies conducted in the US and New Zealand have examined suicide risks and gun ownership, five of which focused on adolescents and used various control groups. ${ }^{4-11}$ All but one of these studies produced a significant positive association between guns in the home and suicide risks with increased risks generally higher for adolescents than for adults. Evaluation of laws in the US and Canada that severely restrict handgun sales and possession also suggest that restricting handgun ownership can decrease suicide rates. ${ }^{12} 13$

Evidence about the relationship between gun ownership and homicide risks is more contro- versial, and subject to limitations. Kellermann et al conducted a case-control study of gun ownership and homicide risks within the home, and reported that gun ownership was associated with a 2.7 -fold increase in homicide risks with increased risks greatest for incidents involving family members and intimate partners (relative risk 7.8, confidence interval (CI) 2.6 to 23.2). ${ }^{14}$ This is consistent with previous research indicating that assaults of intimate partners with guns were much more lethal than assaults that did not involve guns. ${ }^{15}$ Cummings et al carried out a case-control study within a population enrolled in a health maintenance organization and avoided the potential problem of biased reporting of gun ownership by using official records of legal handgun purchases as an indicator of exposure to guns. They report a 2.2-fold increase in homicide risks associated with legal handgun purchase. ${ }^{10}$ However, this association may be, in part, attributable to confounding factors because handgun owners were also at increased risk of non-gun homicides. Given the limitations of research on the gun-homicide link at the individual-or household-level, it is worth noting that ecological and quasiexperimental studies suggest that gun availability and homicide rates are positively associated. ${ }^{12} 1617$

Although many people bring guns into the home for protection against crime, ${ }^{18}{ }^{19}$ research on police reported home invasion crimes indicates that, even in homes with guns, residents were very rarely able to use a gun in self defense. ${ }^{20}$ Measurement of defensive gun uses is a matter of great debate. Surveys have produced estimates of the number of times per year a gun was used in the US for protection against crime that range from 61000 to 23 million, the majority of which reportedly occurred outside the home. ${ }^{21-23}$ Studies such as Kleck and Gertz's estimate 800000 defensive gun uses within the home per year, ${ }^{22}$ but have poor external validity and appear to greatly exaggerate the incidence of defensive gun use. ${ }^{24}$

The link between gun ownership and unintentional shootings has not been formally studied. In the US, unintentional gun deaths are much less common than gun suicides and homicides, however, unintentional shootings still account for approximately 1100 deaths and 17000 non-fatal woundings treated in hospital emergency departments each year ${ }^{25}$ with children and adolescents being common victims both in the US and other countries. ${ }^{26-28}$

With this evidence for the risk posed by guns in the home, the purpose of this study was to determine (1) the prevalence of the belief that homes with guns are safer than homes without
Road, Palo Alto, CA 94304,

USA (e-mail:

khoward@scrdp.stanford.edu) 
Table 1 Characteristics of respondents $*(n=4138)$

\begin{tabular}{|c|c|c|}
\hline Characteristics & No (\%) unweighted & Weighted \\
\hline \multicolumn{3}{|l|}{ Sex } \\
\hline Male & $2068(50)$ & 49 \\
\hline Female & $2070(50)$ & 51 \\
\hline \multicolumn{3}{|l|}{ Age group (years) } \\
\hline $18-34$ & $937(23)$ & 22 \\
\hline $35-65$ & $2395(58)$ & 58 \\
\hline$>65$ & $701(17)$ & 18 \\
\hline \multicolumn{3}{|l|}{ Ethnicity/race } \\
\hline White & $2705(65)$ & 80 \\
\hline African American & $956(23)$ & 8 \\
\hline Other & $434(11)$ & 12 \\
\hline \multicolumn{3}{|l|}{ Education (years) } \\
\hline$\leqslant 12$ & $2378(58)$ & 56 \\
\hline$>12$ & $1760(43)$ & 44 \\
\hline \multicolumn{3}{|l|}{ Income $(\$) \dagger$} \\
\hline$<25000$ & $956(23)$ & 21 \\
\hline $25-54999$ & $1501(36)$ & 37 \\
\hline$\geqslant 55000$ & $958(23)$ & 25 \\
\hline \multicolumn{3}{|c|}{ Children $<18$ living at home } \\
\hline Yes & $1416(34)$ & 33 \\
\hline No & $2378(65)$ & 66 \\
\hline \multicolumn{3}{|c|}{ Political party membership } \\
\hline Democrat & $1613(39)$ & 35 \\
\hline Independent & $1042(25)$ & 27 \\
\hline Republican & $1287(31)$ & 34 \\
\hline \multicolumn{3}{|c|}{ Handgun ownership among respondents } \\
\hline Yes & $868(21)$ & 22 \\
\hline No & $3146(76)$ & 75 \\
\hline \multicolumn{3}{|l|}{ Violent victimization $\ddagger$} \\
\hline Yes & $1311(32)$ & 30 \\
\hline No & $2788(67)$ & 69 \\
\hline \multicolumn{3}{|c|}{ Gun related crime in the neighborhood } \\
\hline Never & $824(20)$ & 22 \\
\hline Rarely & $1659(40)$ & 42 \\
\hline Occasionally & $804(19)$ & 18 \\
\hline Frequently & $703(17)$ & 15 \\
\hline \multicolumn{3}{|c|}{ Trust in the police to keep the neighborhood safe } \\
\hline A lot of trust & $1332(32)$ & 34 \\
\hline Some trust & $1839(44)$ & 44 \\
\hline Very little/no trust & $895(22)$ & 20 \\
\hline
\end{tabular}

*Percentages may not add to 100 because of rounding. Weighted per cents are provided to account for sampling design. $\dagger 17 \%$ of respondents refused.

¥Victimization of respondent, respondent's close friend, or family member.

guns and (2) the factors associated with this belief, specifically personal characteristics and experiences related to violence. This information may increase the understanding of the public's views about the risks of keeping a gun in the home and inform individual and community level efforts to reduce gun injuries.

\section{Method}

SAMPLE

Data are drawn from two cross sectional telephone surveys of registered voters in the US ( $\mathrm{n}=4138)$. Because the data were originally collected as part of a larger study to evaluate a public education campaign about gun violence, surveys were administered at two different times: June 1994 and February 1995. Survey questions asked about awareness of the campaign, experiences with violence, general beliefs about guns, and support for violence prevention interventions. Participants in the two surveys did not differ significantly on any of the study variables of interest and the two samples were therefore combined. The sampling frame consisted of households with telephones in metropolitan statistical areas that included a city with a population of at least 500 000. Respondents were selected using random digit dialing methods. To facilitate subgroup analyses, African Americans were oversampled. This oversampling was achieved by creating a separate sampling frame of phone exchanges that were known to have at least a $30 \%$ African American population. One out of three individuals contacted agreed to participate and $98 \%$ of those who participated completed the entire survey.

\section{MEASURES}

The outcome variable reflects responses to a question asking respondents whether they believed keeping a gun in the home makes the people who live there more or less safe. While "it depends" was not explicitly offered as a response option, it is included in the analysis since nearly one quarter of study participants $(23 \%)$ gave this as an unsolicited response. We also hypothesized that the group responding "it depends" might be substantially different than either the "more safe" or "less safe" groups. If this is true, having three respondent groups provides an opportunity to better understand a group that might be more susceptible to attitudinal change.

Factors hypothesized to influence beliefs about the risks of guns in the home that were examined included: (1) exposure to violence (violent victimization, gun related crime in the neighborhood), (2) fear of violent victimization, (3) trust in the police to keep the neighborhood safe, (4) personal characteristics (sex, age, ethnicity/race, education, household income, and children living at home), and (5) political ideology as measured by self reported major US political party affiliation (Democrafts, Independent, and Republican).

Two measures of exposure to violence were used: (1) previous victimization of the respondent, the respondent's family members, or a close friend, within the past five years and (2) perceived levels of gun related crime in the respondent's neighborhood. To determine potential differences due to type of weapon used by perpetrators, violent victimizations were analyzed in two ways: one variable differentiated between victimizations that involved a gun while the other did not.

The inclusion of variables measuring fear of victimization were used to differentiate those respondents whose fear of victimization is based on actual exposure to violence, by comparison with those who are fearful but have not experienced significant exposure to violence. For example, certain segments of the population such as the elderly and women have higher levels of perceived risk of victimization relative to their actual rates of victimization. ${ }^{18}{ }^{29-32}$

Previous studies have found that as trust in the police decreases, the level of gun ownership increases. ${ }^{33-35}$ As a result, we hypothesized that individuals would be more likely to view guns as protective if they did not trust the police to provide protection.

Respondents were grouped into three age categories: $18-34$ years $(22 \%), 35-65$ years $(58 \%)$, and over 65 years $(18 \%)$. In the US, persons 18-34 years experience the highest rates of gun related homicides and assaults; persons over 65 years of age experience the highest rates of gun related suicides and reported levels of fear of violent crime. ${ }^{36} 37$ 
Table 2 Beliefs about risks associated with a gun in the home by respondent characteristic $^{\star}(n=4138)$

\begin{tabular}{|c|c|c|c|c|c|}
\hline \multirow[b]{2}{*}{ Characteristic } & \multicolumn{5}{|c|}{$\begin{array}{l}\text { Respondents who think home occupants are more safe or less safe } \\
\text { with a gun (\%) }\end{array}$} \\
\hline & $\begin{array}{l}\text { More safe } \\
(n=1169)\end{array}$ & $\begin{array}{l}\text { It depends } \\
(n=971)\end{array}$ & $\begin{array}{l}\text { Less safe } \\
(n=1616)\end{array}$ & $\begin{array}{l}\text { Don't know } \\
(n=382)\end{array}$ & $p$ Valuet \\
\hline \multicolumn{6}{|l|}{ Sex } \\
\hline Male & 36 & 23 & 35 & 7 & \\
\hline Female & 22 & 23 & 45 & 10 & 0.001 \\
\hline \multicolumn{6}{|l|}{ Age group (years) } \\
\hline $18-34$ & 31 & 24 & 40 & 6 & \\
\hline $35-65$ & 29 & 24 & 40 & 8 & \\
\hline$>65$ & 25 & 22 & 41 & 13 & 0.001 \\
\hline \multicolumn{6}{|l|}{ Ethnicity/race } \\
\hline White & 29 & 23 & 40 & 8 & \\
\hline African American & 28 & 26 & 36 & 10 & \\
\hline Other & 30 & 20 & 41 & 10 & 0.30 \\
\hline \multicolumn{6}{|l|}{ Education (years) } \\
\hline$\leqslant 12$ & 32 & 25 & 34 & 9 & \\
\hline$>12$ & 25 & 21 & 47 & 8 & 0.001 \\
\hline \multicolumn{6}{|l|}{ Income $(\$) \ddagger$} \\
\hline$<25000$ & 30 & 24 & 38 & 8 & \\
\hline $25-54999$ & 31 & 23 & 39 & 7 & \\
\hline$\geqslant 55000$ & 26 & 21 & 45 & 8 & 0.01 \\
\hline \multicolumn{6}{|l|}{ Children $<18$ living at home } \\
\hline Yes & 27 & 22 & 45 & 7 & \\
\hline No & 30 & 24 & 37 & 9 & 0.001 \\
\hline \multicolumn{6}{|l|}{ Political party affiliation } \\
\hline Republican & 36 & 25 & 32 & 7 & \\
\hline Independent & 28 & 23 & 40 & 9 & \\
\hline Democrat & 22 & 21 & 48 & 9 & 0.001 \\
\hline \multicolumn{6}{|c|}{ Handgun ownership among respondents } \\
\hline Yes & 56 & 27 & 11 & 6 & \\
\hline No & 20 & 22 & 49 & 9 & 0.001 \\
\hline \multicolumn{6}{|l|}{ Violent victimization $₫$} \\
\hline Yes & 31 & 24 & 38 & 8 & \\
\hline No & 28 & 23 & 41 & 9 & 0.12 \\
\hline \multicolumn{6}{|c|}{ Gun related crime in the neighborhood } \\
\hline Never & 30 & 25 & 36 & 9 & \\
\hline Rarely & 28 & 24 & 41 & 8 & \\
\hline Occasionally & 28 & 21 & 43 & 8 & \\
\hline Frequently & 32 & 23 & 38 & 7 & 0.06 \\
\hline \multicolumn{6}{|c|}{ Trust in the police to keep the neighborhood safe } \\
\hline A lot of trust & 27 & 23 & 41 & 9 & \\
\hline Some trust & 27 & 23 & 42 & 8 & \\
\hline Very little/no trust & 36 & 24 & 32 & 8 & 0.001 \\
\hline Fear of violent victimization $\|$ & $5.6(2.9)$ & $5.9(2.7)$ & $6.0(2.7)$ & $5.7(2.8)$ & 0.003 \\
\hline
\end{tabular}

$\star$ Percentages may not add to 100 because of rounding. Weighted per cents are provided to account for sampling design.

$t \mathrm{p}$ Values for likelihood ratio $\chi^{2}$ test for ordinal predictor variables and one way analysis of variance for continuous predictor variables.

$\$ 17 \%$ of respondents refused.

SVictimization of respondent, respondent's close friend, or family member.

U Mean scores and standard deviations. Measured on a scale of 1 to 10 with $1=$ "not worried at all" and $10=$ "extremely worried about members of your family or close friends becoming a victim of violent crime".

Other demographic factors may also be associated with beliefs about guns in the home. For example, African Americans who are disproportionately affected by gun violence, ${ }^{38-40}$ and respondents with children, may be more concerned about the safety of having guns in the home. Those with higher levels of education and income are more likely to take measures to protect their health (for example, wear seat belts, exercise). ${ }^{41}{ }^{42}$ Beliefs about guns and gun policy are also strongly associated with self reported political party affiliation. ${ }^{43-45}$ Therefore, we hypothesized that Republicans would be more likely than Independents or Democrats to believe that guns make a home more safe. Because handgun owners commonly cite protection as one of the primary reasons for owning a handgun, ${ }^{18}{ }^{19}$ we hypothesized that handgun owners would be more likely to believe in the protective value of guns in the home. Since the ownership of long guns (rifles and shotguns) for protection in urban areas within the US is uncommon, we did not focus on this type of ownership.
DATA ANALYSIS

For all analyses, sampling weights were applied to adjust for oversampling of African Americans. The outcome variable, beliefs about whether a gun in the home makes a home more safe or less safe, was cross tabulated with each independent variable. The statistical significance of these bivariate relationships was evaluated using the likelihood ratio $\chi^{2}$ test when the independent variable was categorical and one way analysis of variance when the independent variable was continuous. Multinomial logistic regression analysis was used to examine the relationship between each independent variable and the outcome variable while simultaneously controlling for other variables in the model. ${ }^{46}$

Although all respondents are included in our univariate and bivariate analyses, several factors required exclusion of some respondents for the multivariate analysis. Multinomial logistic regression analysis does not reliably identify the best model fit when variables with small categorical percentages are included in the model. Therefore, ethnic/racial groups that comprised fewer than $5 \%$ of the sample population were excluded. Similarly, respondents who stated that they did not know whether a gun in the home was more protective or perilous $(9 \%)$ were excluded. Twenty five per cent of the cases $(n=1034)$ were also excluded in the final model due to the exclusions mentioned above or to missing information concerning one or more variables of interest. Refusal and "don't know" responses comprised most of the missing information, and ranged from less than $1 \%$ to $3.8 \%$ for individual variables in the final model.

Handgun ownership is more likely to be a consequence of an individual's belief about the risks and benefits of keeping a gun in the home rather than a cause of those beliefs. Including handgun ownership in the model could, therefore, account for variance due to precursors of beliefs about guns and safety, and add little to our understanding of the determinants of those beliefs. For this reason, we chose not to include handgun ownership in the final model. Because $17 \%$ of respondents $(n=626)$ eligible for inclusion refused to disclose their income, income was also excluded from multivariate analysis. Other variables were excluded from the final multivariate model if they were not significantly associated with the outcome and their exclusion did not substantially alter the parameter estimates for the other covariates. This enabled us to identify the most parsimonious model that included all relevant confounders for which data were available.

\section{Results}

Twenty nine per cent of the respondents believed keeping a gun in the home makes the home more safe, $40 \%$ said it makes it less safe, $23 \%$ said "it depends", and 9\% said "don't know". Respondent characteristics are described in table 1.

Table 2 shows that groups more likely to believe that a gun in the home increases safety 
Table 3 Characteristics associated with the belief that keeping a gun in the home makes the people who live there more safe or less safe $(n=3078)$; multinomial logistic regression results, odds ratio (95\% confidence interval)

\begin{tabular}{|c|c|c|c|}
\hline Characteristics & More safe & It depends & Less safe \\
\hline \multicolumn{4}{|l|}{ Sex } \\
\hline Female & $1.0+$ & 1.0 & 1.0 \\
\hline Male & $2.4(2.1$ to 2.9$)$ & $1.6(1.3$ to 1.9$)$ & $0.26(0.18$ to 0.38$)$ \\
\hline \multicolumn{4}{|l|}{ Age group (years) } \\
\hline$>65$ & 1.0 & 1.0 & 1.0 \\
\hline $35-65$ & $2.3(0.97$ to 5.4$)$ & $1.20(0.56$ to 2.3$)$ & $0.38(0.08$ to 1.8$)$ \\
\hline$<34$ & $2.0(0.86$ to 4.9$)$ & $1.62(0.64$ to 2.6$)$ & $0.38(0.08$ to 2.6$)$ \\
\hline \multicolumn{4}{|l|}{ Ethnicity/race } \\
\hline White & 1.0 & 1.0 & 1.0 \\
\hline African American & $1.1(0.79$ to 1.5$)$ & $1.47(1.1$ to 2.0$)$ & $0.63(0.34$ to 1.2$)$ \\
\hline \multicolumn{4}{|l|}{ Education (years) } \\
\hline$>12$ & 1.0 & 1.0 & 1.0 \\
\hline$\leqslant 12$ & $1.8(1.5$ to 2.1$)$ & $1.7(1.4$ to 2.0$)$ & $0.34(0.24$ to 0.49$)$ \\
\hline \multicolumn{4}{|l|}{ Children $<18$ living at home } \\
\hline Yes & 1.0 & 1.0 & 1.0 \\
\hline No & $1.3(1.1$ to 1.6$)$ & $1.3(1.1$ to 1.6$)$ & $0.58(0.40$ to 0.85$)$ \\
\hline \multicolumn{4}{|l|}{ Political party membership } \\
\hline Democrat & 1.0 & 1.0 & 1.0 \\
\hline Independent & $11.1(6.1$ to 20.1$)$ & $3.7(1.9$ to 7.4$)$ & $0.02(0.01$ to 0.09$)$ \\
\hline Republican & $16.6(9.2$ to 29.7$)$ & $5.0(2.6$ to 9.8$)$ & $0.01(0.003$ to 0.04$)$ \\
\hline \multicolumn{4}{|c|}{ Trust in the police to keep the neighborhood safe } \\
\hline A lot of trust & 1.0 & 1.0 & 1.0 \\
\hline Some trust & $1.28(1.25$ to 1.3$)$ & $1.2(1.1$ to 1.2$)$ & 0.69 (0.66 to 0.72$)$ \\
\hline Very little/no trust & $4.5(2.1$ to 9.2$)$ & $3.6(1.8$ to 7.2$)$ & $0.06(0.02$ to 0.26$)$ \\
\hline Fear of violent victimization $\ddagger$ & $1.0(0.97$ to 1.1$)$ & $1.0(0.97$ to 1.1$)$ & $0.97(0.90$ to 1.1$)$ \\
\hline
\end{tabular}

${ }^{\star}$ Twenty five per cent of cases were excluded due to missing information concerning one or more variables of interest. Violent victimization and perceived level of firearm related crime in the neighborhood were excluded from the final model.

†For comparison purposes, odds ratios for reference categories were set at 1.0.

$\ddagger$ Measured on a scale of 1 to 10 with $1=$ "not worried at all" and $10=$ "extremely worried about members of your family or close friends becoming a victim of violent crime".

include males, Republicans, handgun owners, and those who had very little or no trust in the police to keep the neighborhood safe. Having 12 years of education or fewer, or having no children living at home, were each associated with the belief that guns in the home generally enhance the safety of its occupants.

The multinomial logistic regression analysis controlled for the effects of other variables, but, with few exceptions, produced results (table 3) similar to the bivariate analyses (table 2). Compared with respondents with "a lot of trust" in the police, those with "very little" or "no trust" in the police were much more likely to believe that keeping a gun in the home increased household safety (odds ratio (OR) $4.5 ; 95 \%$ CI 2.1 to 9.2). Those with "some trust" in the police were slightly more likely than those with "a lot of trust" in the police to believe that a gun would make a home safer (OR 1.28 ; 95\% CI 1.25 to 1.3 ).

Previous violent victimization and perceived level of gun related crime in the neighborhood were not associated with beliefs about a gun in the home. Findings did not differ by whether or not the violent victimization was committed with a gun, therefore these variables were excluded from the final analysis.

The multinomial logistic regression analysis also showed that being male, having 12 years or fewer of education, and no children living at home was associated with the belief that keeping guns in the home makes it safer. African Americans were more likely to respond that the risks and benefits depend on other factors as compared with whites (OR 1.5; 95\% CI 1.1 to 2.0).

Political party affiliation was also strongly and independently associated with beliefs about gun risks and benefits. Compared with
Democrats, Republicans (OR 16.6; 95\% CI 9.2 to 29.7 ) and Independents (OR $11.1 ; 95 \%$ CI 6.1 to 20.1 ) were much more likely to believe they were more safe with a gun in the home.

For most of the independent variables, the odds ratios for survey participants who responded "it depends" were similar in direction, but of lesser magnitude, to those responding "more safe". For instance, men were more likely than women to respond more safe (OR $2.4 ; 95 \%$ CI 2.1 to 2.9 ), more likely to respond it depends (OR, 1.6; 95\% CI 1.3 to 1.9 ), and less likely to respond less safe (OR $0.26 ; 95 \%$ CI 0.18 to 0.38 ).

A sensitivity analysis demonstrated that the findings were substantially unchanged when income was included in the final model. A separate sensitivity analysis showed that the inclusion of handgun ownership in the final model did not affect other estimates. The one exception was the association between age and beliefs about gun risks. With handgun ownership in the model, the youngest and middle aged respondents were 2.0 (95\% CI, 1.6 to 2.3 ) and 1.7 times (95\% CI, 1.2 to 2.1 ) more likely, respectively, to believe that they were more safe with a gun in the home as compared with the oldest respondents.

\section{Discussion}

To our knowledge, this is the first study of individuals' beliefs about the effects of keeping a gun in the home on household safety. The large sample size and oversampling of African Americans provided an opportunity to assess the views of a group disproportionately affected by violence with a relatively high level of precision. Although the large US sample enhances the generalizability of our study, the focus on registered voters in large metropolitan areas precludes us from generalizing the findings to persons living in small cities or rural areas, or to individuals who are not registered to vote. Different factors may be associated with these groups' beliefs about the protective nature of firearms in the home. For example, those living in rural areas are more likely to own guns for other reasons besides protection (for example, hunting) and individuals who are not registered to vote are more likely to be poorer and disproportionately affected by crime.

Our inability to include racial groups other than whites and African Americans in multivariate analysis may also limit the generalizability of the findings. The bivariate analyses indicated that, as a group, individuals falling into the "other" racial and ethnic group held views about guns and safety that were similar to those of whites. Nevertheless, there may be important differences among racial and ethnic groups represented in this heterogeneous category.

While the response rate was relatively low, other than somewhat higher reported levels of education, the sample population was similar to the US Bureau of Census information on the national electorate in regard to sex, ethnicity/ 
race, age, and income. ${ }^{47}$ Prevalence of gun ownership among respondents was also similar to estimates from other national surveys. ${ }^{18}$

As exposure to violence was limited to two questions that did not distinguish personal victimization from that of family or friends, additional questions about the type of violent victimization, its frequency and location, and the relationship of the perpetrator to the victim may provide a more comprehensive picture of how exposure to violence affects beliefs about the risks associated with keeping a gun in the home.

Only $40 \%$ of our study population believes that keeping a gun in the home makes it "less safe". Those most likely to believe they are safer with a gun in the home include: males, those with at most a high school education, individuals with no children living at home, Republicans, and those with very little or no trust in the police.

Although beliefs about the relative protection and risks provided by guns may indeed reflect risk awareness gaps, the associations may also reflect real differences in risks among the groups being compared. For example, risks associated with keeping guns in the home may be greater for households with children and adolescents. Children's future risk of death may also be affected by parents' attitudes about keeping a gun in the home since gun ownership as an adult is associated with growing up in a household with a firearm. ${ }^{23}$ Although epidemiologic studies indicate that, on average, keeping a gun in the home is more perilous than protective, ${ }^{9}{ }^{14}$ this relationship (or at least the strength of it) is likely to vary depending on the characteristics of the household and its members.

The two direct measures for exposure to violence did not predict the belief that it is safer to keep a gun in the home. However, groups at highest risk for violence, young adults and males, ${ }^{36}{ }^{37}$ were more likely than groups at lower risk-older adults and females-to believe that keeping a gun in the home increases safety.

Republican party affiliation and lack of trust in the police to provide protection were the variables most strongly associated with the belief that keeping a gun in the home enhances household safety. As a group, Republicans may be more skeptical of some collective efforts to address social problems, such as crime (particularly if those efforts involve government institutions), and more likely to believe that individuals should be responsible for their own welfare. Therefore, our findings suggest that skepticism about the effectiveness of collective measures to address crime may be closely tied to the belief that one's household is safer with a gun than without one.

\section{Implications for prevention}

A variety of methods are currently used to educate people about the potential risks associated with gun ownership including media campaigns, community health education campaigns, and anticipatory guidance by health care providers. Our findings can assist the development and implementation of these efforts by providing insight into the cluster of characteristics associated with the belief that keeping a gun in the home makes it more safe rather than less safe.

Although these findings enhance our understanding of individuals' beliefs about the risks and benefits of keeping guns in the home, additional qualitative research is needed to assess what educational strategies would actually change those attitudes as well as gun acquisition. For example, it is unclear how easy it would be to enhance public confidence in the ability of the police to provide protection against home intrusion. But people who lack confidence in the police may find alternative means of home protection more acceptable if the risks of keeping guns in the home are underscored.

It may be especially advantageous to focus intervention efforts on the group who responded "it depends". This group may be more receptive to gun safety interventions since they already believe that situations exist in which guns in the home make household members less safe.

Although the patterns of gun ownership ${ }^{48}$ and reasons for gun ownership in other countries (for example, cultural, political) may differ, individuals throughout the world who keep guns in the home are at risk of gun injuries. While the investigation of unique factors associated with beliefs about the protective nature of guns in the home in other countries is needed, this study may provide a basis for additional studies and interventions outside of the US.

This study was supported in part by a grant from the California Wellness Foundation and the Joyce Foundation.

1 Cummings P, Koepsell TD. Does owning a firearm increase or decrease the risk of death? FAMA 1998;28:471-3.

2 Kleck G. What are the risks and benefits or keeping a gun in the home? $7 A M A$ 1998;280:473-5.

3 Miller M, Hemenway D. The relationship between firearms and suicide: a review of the literature. Aggression and Violent Behavior 1999;4:59-75.

4 Brent DA, Perper JA, Goldstein CE, et al. Risk factors for adolescent suicide: a comparison of adolescent suicide victims with suicidal inpatients. Arch Gen Psychiatry 1988;45: 581-5.

5 Brent DA, Perper JA, Allman CJ, et al. The presence and accessibility of firearms in the homes on adolescent suicides. FAMA 1991;266:2989-95.

6 Brent DA, Perpler JA, Moritz G, et al. Suicide in adolescents with no apparent psychopathology. $f$ Am Acad Child Adolesc Psychiatry 1993;147:1066-71.

7 Brent DA, Perper JA, Moritz G, et al. Firearms and adolescent suicide: a community case-control study. Am $\mathcal{F}$ Dis Child 1993;147:1066-71.

8 Brent DA, Perpler JA, Moritz G, et al. Suicide in affectively ill adolescents: a case-control study. $\mathcal{F}$ Affect Disord 1994;31:193-202.

9 Kellermann AL, Rivara FP, Somes G, et al. Suicide in the home in relation to gun ownership. $N$ Engl $f \mathrm{Med}$ 1992;327:467-72.

10 Cummings P, Koepsell TD, Grossman DG, et al. The association between purchase of a handgun and homicide or suicide. Am $\mathcal{F}$ Public Health 1997;87:974-8.

11 Beautrais AL, Joyce PR, Mulder RT. Access to firearms and the risk of suicide: a case-control study. Aust NZ F Psychiatry 1996;30:741-8

12 Loftin C, McDowall D, Wiersema B, et al. Effects of restrictive licensing of handguns on homicide and suicide in the District of Columbia. N Engl F Med 1991;325:1615-20.

13 Carrington PJ, Moyer S. Gun control and suicide in Ontario. Am f Psychiatry 1994;151:606-8.

14 Kellermann AL, Rivara FP, Rushforth NB, et al. Gun ownership as a risk factor for homicide in the home. $N$ Engl $\mathcal{F}$ Med 1993;329:1084-91. 
15 Saltzman LE, Mercy JA, O'Carroll PW, et al. Weapon involvement and injury outcome in family and intimate involvement and injury outcom
assaults. $¥ A M A 1992 ; 267: 43-7$.

16 McDowall D. Firearm availability and homicide rates in Detroit, 1951-1986. Social Forces 1991;69:1085-101.

17 Programme Evaluation Section. A statistical analysis of the impact of the 1979 firearms control legislation. Canada: Department of Justice, 1996.

18 Maguire K, Pastore AL, eds. Sourcebook of criminal justice statistics 1994. Washington, DC: US Department of Justice, 1995.

19 Hemenway D, Slonick SJ, Azrael DR. Firearm training and storage. $\mathcal{F} A M A$ 1995;273:46-50.

20 Kellermann AL, Westphal L, Fischer L, et al. Weapon involvement in home invasion crimes. $7 A M A$ 1995;273: 1759-62.

21 Rand MR. Guns and crime: handgun victimization, firearm self-defense, and firearm theft. Washington, DC: US Departself-defense, and firearm theft. Washington, DC: US D

22 Kleck G, Gertz M. Armed resistance to crime: the prevalence and nature of self-defense with a gun. fournal of prevalence and nature of self-defense with a gun

23 Cook PJ, Ludwig J. Guns in America: national survey on private ownership and use of firearms. Washington, DC: National Institute of Justice, 1997.

24 Hemenway D. Survey research and self-defense gun use: an explanation of extreme overestimates. Fournal of Criminal Law and Criminology 1997;87:1430-45.

25 Peters KD, Kochanek KD, Murphy SL. Deaths: final data for 1996. National Vital Statistics Report 1998;47(9).

26 Sinauer N, Annest JL, Mercy JA. Unintentional, nonfatal firearm-related injuries. $7 A M A$ 1996;275:1740-3.

27 Lee RK, Harris MJ. Unintentional firearm injuries: the price of protection. Am f Prev Med 1993;9:16-20 (suppl).

28 Centers for Disease Control and Prevention. Rates of homicide, suicide, and firearm-related death among children-26 industrialized countries. Morb Mortal Wkly Rep 1997;46:101-5.

29 Janson P, Ryder LK. Crime and the elderly: the relationship between risk and crime. Gerontologist 1983;23:207-12.

30 Thompson C, Bankston WB, Pierre RL. Parity and disparity among three measures of fear of crime: a research note. Deviant Behavior 1992;13:373-89.

31 Bankston WB, Jenkins QA, Thayer-Doyle CL, et al. Fear of criminal victimization and residential location: the influence of perceived risk. Rural Sociology 1987;52:98-107.

32 Bureau of Justice Statistics. National Crime Victimization Survey: criminal victimization 1994 (NCF-1580d
ington, DC: US Department of Justice, 1996.
33 McDowall D, Loftin C. Collective security and the demand for legal handguns. American Fournal of Sociology 1983; 88: $1146-61$.

34 Feagin JR. Home-defense and the police. American Behavior Science 1970;13:797-814.

35 Clotfelter CT. Crimes, disorders, and the demand for handguns: an empirical analysis. Law Policy Quarterly 1981;3:425-41

36 Fingerhut LA, Jones C, Makuc DM. Firearm and motor vehicle injury mortality: variations by state, race, and ethnicity: United States, 1990-1991. Advance data from vital and health statistics. Hyattsville, MD: National Center for Health Statistics. 1994;242:1-12.

37 Perkins CA, Klaus PA, Batian LD, et al. Criminal victimization in the United States 1993: a National Crime Victimization Survey report. Washington, DC: US Department of Justice, 1996.

38 Singh GK, Kochanek KD, MacDorman MF. Advance report of final mortality statistics, 1994. Monthly Vital Statistics Report 1996;45(suppl 3).

39 Fingerhut LA, Ingram DD, Feldman JJ. Firearm and nonfirearm homicide among persons 15 through 19 years of age: differences by level of urbanization, United States 1979 through 1989. ҰAMA 1992;267:3048-53.

40 Centers for Disease Control and Prevention. Suicide among children, adolescents and young adults-United States, 1980-1992. Morb Mortal Wkly Rep 1995;44:289-91.

41 Cleary PD. Why people take precautions against health risks. In: Weinstein N, ed. Taking care: understanding and encouraging self protective behavior. New York: Cambridge University Press, 1987

42 Adler NE, Boyce T, Chesney MA, et al. Socioeconomic staus and health: the challenge of the gradient. Am Psychol $1994 ; 49: 15-24$

43 Gallup Organization. Most Americans see crime on the rise. Gallup Poll Monthly 1993;339:18-27.

44 Gallup Organization. Support for gun control at all time high: public see links between drugs and crime. Gallup Poll Monthly 1990;300:34-9.

45 Gallup Organization. Federal ban on assault guns backed by large majority. Gallup Poll Monthly 1989;282:2-5.

46 Hosmer DW, Lemeshow S. Applied logistic regression. New York: John Wiley, 1989.

47 Casper L. Voting and registration in the election of November 1994 (PPL-25). Washington, DC: Bureau of the Census, 1995

48 Killias M. International correlations between gun ownership and rates of homicide and suicide. Can Med Assoc F 1993; 148:1721-5.

\section{Write lines on the road}

Motorists caught breaking the rules of the road in Colombia are being forced by police to write "I must obey traffic laws" 10 times on a card. Colonel Alberto Guervara, the traffic police chief in the capital, Bogota, explained, "Sometimes, like with kids, you have to make them understand" (Mail on Sunday (London), June 1999).

\section{Accident cases}

A 4 year old boy drowned in a Donegal bog in Ireland while his father and uncle were cutting turf nearby. He was only missing for 10 minutes before his father found his body in a drain in the bog (Belfast Telegraph, June 1999).

A 13 month old boy died from an electric shock after brushing against a fire while playing at a friend's house. He was with his teenage mother at the time and the fire was not switched on (Daily Telegraph (London), June 1999).

A shocked driver raced to help a tot who fell under his van and found it to be his son. He was on the ground with serious head and leg injuries. The boy had climbed on to the bull bars fitted to the van and fell off as his father drove away (Sun (London), June 1999).

Horror writer Stephen King may not be able to walk for a year after sustaining an injury in June. He was struck from behind by a van as he walked along a road near his summer home in Maine. The driver of the van who lost control when he was distracted by his dog, will not be charged (Mail on Sunday (London), June 1999).

The daughter of singer Julio Iglesias was seriously injured in a car smash in Los Angeles. She was flung from a car driven by her boyfriend when it hit another vehicle, and then flipped over five times (Sun (London), June 1999). 